OPEN ACCESS

Edited by:

Saeed Farooq

Keele University, United Kingdom

Reviewed by:

Andrew Tomita,

University of KwaZulu-Natal,

South Africa

Vidyullatha Peddireddy,

Gandhi Institute of Technology and

Management (GITAM), India

*Correspondence:

Liqun Zhang

liqunzhang2005@sina.com

Liyuan Guo

guoly@psych.ac.cn

†These authors have contributed equally to this work and share first authorship

Specialty section:

This article was submitted to

Public Mental Health,

a section of the journal

Frontiers in Psychiatry

Received: 02 March 2021

Accepted: 16 August 2021

Published: 07 September 2021

Citation:

Liu K, Zhang Y, Qu S, Yang W, Guo L and Zhang $L$ (2021) Prevalence and Correlates of Anxiety and Depressive

Symptoms in Patients With and

Without Multi-Drug Resistant Pulmonary Tuberculosis in China.

Front. Psychiatry 12:674891.

doi: 10.3389/fpsyt.2021.674891

\section{Prevalence and Correlates of Anxiety and Depressive Symptoms in Patients With and Without Multi-Drug Resistant Pulmonary Tuberculosis in China}

\author{
Kewei Liu ${ }^{1 \dagger}$, Yidan Zhang ${ }^{2,3 \dagger}$, Shilin $\mathrm{Qu}^{4 \dagger}$, Wenying Yang ${ }^{1}$, Liyuan Guo ${ }^{2,3 *}$ and \\ Liqun Zhang ${ }^{1 \star}$
}

${ }^{1}$ Department of Tuberculosis, Capital Medical University, Beijing Chest Hospital, Beijing, China, ${ }^{2}$ Chinese Academy of Sciences Key Laboratory of Mental Health, Institute of Psychology, Chinese Academy of Sciences, Beijing, China, ${ }^{3}$ Department of Psychology, University of Chinese Academy of Sciences, Beijing, China, ${ }^{4}$ Department of Multidrug Resistance Tuberculosis, Jingzhou Infectious Diseases and Chest Hospital, Jingzhou, China

China is still among the 30 high-burden tuberculosis (TB) countries in the world and TB remains a public health concern. TB can be a cause of mental illness, with prolonged treatment and several anti-TB drugs leading to extreme mental health problems such as depression and anxiety in TB patients. To investigate the prevalence of anxiety and depressive symptoms among TB patients, and to explore whether drug resistance is a covariate for depressive and anxiety symptoms, a total of 167 pulmonary tuberculosis patients were enrolled in this study, which was conducted from January 1 to September 30, 2020. Data were collected, using a structured questionnaire with a demographic component, the Hospital Anxiety and Depression Scale (HADS), General Health Questionnaire 20 (GHQ-20), the Tuberculosis-related Stigma Scale (TSS) and the Social Support Rating Scale (SSRS). Association between demographics, disease/treatment characteristics, stigma, social support, and anxiety/depression symptoms were investigated either based on Pearson's correlation coefficient or group comparisons based on independent $t$-test (or Mann-Whitney U-test) Multiple linear stepwise regression analysis was used for determining the predictors of anxiety and depression. The results showed that multi-drug resistance pulmonary tuberculosis patients were associated with anxiety challenges. Multiple linear regression analysis indicated that self-esteem accounted for 33.5 and $38 \%$ of the variation in anxiety and depression, respectively. This shows that among tuberculosis patients, self-esteem is the factor that could most explains the depression and anxiety symptoms of patients, suggesting that we may could through improving the environment, society, and family respect and tolerance of tuberculosis patients, thereby improving the mental health of tuberculosis patients.

Keywords: tuberculosis, TB stigma, social supports, depression, anxiety, drug-resistant 


\section{INTRODUCTION}

Tuberculosis (TB) is a chronic infectious disease caused by mycobacterium tuberculosis. It is one of the leading causes of morbidity and mortality worldwide (1). According to the World Health Organization's 2019 report, there are about one-quarter of the world's population has latent TB,10 million people are infected with TB each year, 484,000 of whom are drug-resistant TB (of which $78 \%$ have the MDR-TB), and 1.5 million people die of TB each year. China is still among the 30 high-burden $\mathrm{TB}$ countries in the world, and $\mathrm{TB}$ remains a public health concern (2).

Anxiety and depression are the most common mental disorders in the general population. The presence of anxiety and depression has a negative impact on quality of life, healthcare costs and self-care (3). Patients with TB may suffer from mental disorders as a result of long-term treatment, anti-TB drug side effects and TB relapses (4). Studies on the prevalence of anxiety and depression in TB patients in different countries or regions showed that the prevalence of anxiety and depression in TB patients is about $40.67-72.88 \%$ and $9.93-61 \%$, respectively $(3,5-$ 8). A study in China showed that the prevalence of anxiety and depression in TB patients is about 18.37 and $18.13 \%$, respectively (4).

TB can be a cause of mental illness, with prolonged treatment and several anti-TB drugs (such as cycloserine) leading to extreme mental health problems such as anxiety and depression (4). Mental illness complications have been associated with antituberculosis therapy since the 1950s. The possible environmental and genetic factors of anti-TB medicationinduced adverse reactions have always been the matter of concern (9). In addition, TB patients continue to experience significant social discrimination and increased stigma (10). Since they have tuberculosis, the patients might be discriminated at workplace and public areas as the disease is airborne. In addition, prevailing weakness caused due to the disease would lead to inefficient work and result in unemployment and negative events in life. There is evidence that these factors can cause patients to stop treatment, increase feelings of alienation, and lead to extreme forms of selfharm, including suicide (11-13). However, little is known about the prevalence of anxiety and depression among TB patients in China, studies on effect of MDR-TB/ treatment in causing anxiety and depression are meager.

This study aimed to investigate the prevalence and correlates of anxiety and depressive symptoms among pulmonary $\mathrm{TB}$ patients, and explore whether TB-drug resistance was associated with greater anxiety and depressive symptoms.

\section{MATERIALS AND METHODS \\ Study Design}

A cross-sectional design was conducted.

\section{Study Site}

This study was conducted in two hospitals: (1) the Beijing Chest Hospital, Beijing China and (2) JingZhou Chest Hospital, JingZhou city, HuBei province, that care for patients with TB.

\section{Subjects}

From January 1 to September 30, 2020, a convenience sample of 167 patients who were hospitalized, under treatment, or newly diagnosed were recruited. Inclusion criteria: (1) TB patients meeting the diagnostic criteria: drug-sensitive TB was based on drug susceptibility testing which showed that mycobacterium tuberculosis were susceptible to all of the antiTB drugs; MDR-TB was based on drug susceptibility testing which showed that mycobacterium tuberculosis were resistant to at least isoniazid and rifampicin simultaneously. (2) No other serious somatic diseases; (3) Clear consciousness and cognitive abilities; (4) Ability to complete the questionnaire independently. Exclusion criteria: (1) Pregnant, children, seriously ill or with communication problems; (2) Patients with serious diseases, such as cancer, HIV; (3) The diagnosis of TB is not clear; (4) Antidepressant use during the investigation period.

\section{Data Collection}

Data were collected using an online structured questionnaire and filled out by the patients using their own smartphones or tablets. The questionnaire included demographic information such as gender, age, education, course of TB, drug resistance states, times of treatments, treatment outcome, etc. The Hospital Anxiety and Depression Scale (HADS) and The General Health Questionnaire 20 (GHQ-20) were included in the questionnaire to evaluate patient depressive and anxiety symptoms. The Tuberculosisrelated Stigma Scale (TSS) was used to evaluate stigma of the patients. The Social Support Rating Scale (SSRS) was used to evaluate the social support. All the scales were the Chinese versions, which were valid and efficient.

\section{The Hospital Anxiety and Depression Scale}

The scale is a 14-items self-rating scale, addressing anxiety/depression related issues in the previous 2 weeks. The Chinese version of HADS is wildly used in china and was found to be a reliable measurement tool for excluding depression and anxiety in patients with the Cronbach's alpha coefficients of the HADS-A and HADS-D subscales were 0.753 and 0.764 , respectively (14). It is composed of two subscales, anxiety (HADS-A) and depression (HADS-D), each consisting of 7 items. Likert 4 score ( $0-3$ points) is used for each item. Zigmond divided the subscale scores as follows: $0-7$ in normal state, $8-10$ in suspicious state, and 11-21 in positive state (15). Therefore, in this study, the critical value is 8.The overall HADS score was divided into normal state (0-14) and mental illness symptom (15-42). HADS has been widely used in the screening of clinical patients' psychological problem. A previous study reported that the correlation coefficient of the two HADS subscales was $0.40-0.74$ with an average of 0.56 , and Cronbach's coefficient was 0.83 and 0.82 , respectively, which proved that the scale had good reliability and validity (16).

\section{General Health Questionnaire 20}

The General Health Questionnaire was revised in Chinese version (17). This self-report questionnaire comprises a total of 20 items, including self-esteem ( 9 items), depression scale (6 items), and anxiety scale (5 items), participants were all asked 
to use "yes" or "no" to indicate how they had felt in last 2 weeks. From 1 to 9 , self-esteem scale is a measure of the positive direction of mental health. The score range is $0-9$. Questions 10-15 are the depression scale, and questions 16-20 are the anxiety scale. These two scales measure the negative direction of mental health.

\section{The Tuberculosis-Related Stigma Scale}

The TSS was a self-rating scale which developed by Yang Tingting to assess patients' perceptions of TB stigma in the last 2 weeks, which has 9 items. The score of all items is the patient's stigma score, which ranges from 0 to 27 points. The higher score refers to the higher stigma of tuberculosis patient. The overall Cronbach coefficient of the scale was 0.88 , and the Cronbach coefficient of each dimension was $0.85,0.60$, and 0.66 . Confirmatory factor analysis showed that the scale had reliable structural validity and was suitable for Chinese cultural background (18).

\section{The Social Support Rating Scale}

Social support was measured by the Social Support Rating Scale (SSRS), which was edited to Chinese version in 1999 by SY Xiao. It is a self-rating scale which include 10 -item survey originally designed to assess three different dimensions of social support: subjective support (4 items), objective support (3 items), and support-seeking behavior ( 3 items). Subjective support reflects the perceived interpersonal supports which an individual can count on. Objective support reflects the degree of actual support an individual received in the past. Support-seeking behavior refers to the different patterns of behavior that an individual would utilize when trying to seek social support. A higher score indicates more social support. participants were all asked to use "yes" or "no" to indicate how they had felt in last 2 recent weeks. The Chinese version of SSRS shows a high reliability which exceeded 0.92 (19). The SSRS has been widely applied in Chinese population because of its high reliability and validity (20).

\section{Statistical Analysis}

(1) The patients' demographic and disease characteristics were analyzed with descriptive statistics. (2) Pearson's correlation analysis was used to study the correlation between two continuous data, including TB-related stigma, social support, duration of disease, self-esteem, anxiety and depression. (3) Independent sample T-test or Mann-Whitney $U$-test as appropriate was used for comparison psychological health level (anxiety and depression)between TB patients with sensitive and MDR-TB. (4) Multiple linear stepwise regression analysis was conducted to explore risk factors for HADS anxiety and HADS depression, statistical test level $\leq 0.05$. All statistical analyses were performed using Statistical Package for Social Sciences (SPSS) version 25.0 for Windows.

\section{Ethical Considerations}

Ethical approval (LW-01) was obtained from the Institutional Ethical Review Board of Beijing Chest Hospital, Beijing, China. In addition, research permission was obtained from the hospital. All patients provided written informed consent to participate in this study. After data collection and analysis, we contacted
TABLE 1 | Characteristics of TB patients.

\begin{tabular}{|c|c|c|c|}
\hline Characteristic & Mean \pm SD & $n$ & (\%) \\
\hline \multicolumn{4}{|l|}{ Age } \\
\hline$<18$ & & 2 & 1.20 \\
\hline $18-25$ & & 35 & 20.96 \\
\hline $26-30$ & & 32 & 19.16 \\
\hline $31-40$ & & 38 & 22.75 \\
\hline $41-50$ & & 39 & 23.35 \\
\hline $51-60$ & & 17 & 10.18 \\
\hline Above 60 & & 4 & 2.40 \\
\hline \multicolumn{4}{|l|}{ Sex } \\
\hline Male & & 92 & 55.09 \\
\hline Female & & 75 & 44.91 \\
\hline \multicolumn{4}{|l|}{ Education level } \\
\hline Beneath the bachelor & & 113 & 67.66 \\
\hline Bachelor & & 45 & 26.95 \\
\hline Master or above degree & & 9 & 5.39 \\
\hline Duration of Tuberculosis (month) & $21.37 \pm 28.44$ & & \\
\hline \multicolumn{4}{|l|}{ Drug resistance } \\
\hline No drug resistance & & 65 & 38.92 \\
\hline Drug resistance & & 102 & 61.08 \\
\hline \multicolumn{4}{|l|}{ Treatment times } \\
\hline Once & & 100 & 59.88 \\
\hline Twice & & 43 & 25.75 \\
\hline Third & & 8 & 4.79 \\
\hline Fourth & & 5 & 2.99 \\
\hline More & & 11 & 6.59 \\
\hline \multicolumn{4}{|l|}{ Treatment outcome } \\
\hline Being cured & & 47 & 28.14 \\
\hline In the treatment & & 120 & 71.86 \\
\hline
\end{tabular}

the patients with depressive and anxiety symptoms by using wechat and suggested them undergo further evaluation at the department of mental disease.

\section{RESULTS}

\section{Demographic and Disease Characteristics}

As shown in Table 1, among the 167 patients, 92 were male (55.09\%) and 75 were female (44.91\%). The age distribution was normal, and the proportion of patients with bachelor degree or less was higher, which is $67.66 \%$. There were $65(38.92 \%)$ patients with drug sensitive PTB and 102 (61.08\%) patients with MDRPTB. 100 patients were in the first treatment (59.88\%) and 120 patients under treatment (71.86\%).

\section{Prevalence of Depressive and Anxiety Symptoms Among TB Patients}

According to the HADS, the mean anxiety score of all patients was $5.96(\mathrm{SD}=4.11)$, and depression score of all patients was $5.56(\mathrm{SD}=4.58)$. A total of $49(29.34 \%)$ TB patients were found to have anxiety symptoms and $50(29.94 \%) \mathrm{TB}$ patients were found to have depressive symptoms. A total of 40 (23.95\%) TB 
patients had both depressive and anxiety symptoms. According to the GHQ-20, the mean anxiety score and mean depression score of all patients were $1.59(\mathrm{SD}=1.91)$ and $1.19(\mathrm{SD}=1.72)$ respectively, and mean self-esteem score of all patients was 5.74 $(\mathrm{SD}=2.77)$.

\section{Correlation Analysis of Stigma, Social Support, Self-Esteem, Duration of Disease, and Mental Health Scores of TB Patients}

Table 2 shows that the psychological health problem is widely positively correlated with TSS and duration of disease $(p<$ 0.01 ), but widely negatively correlated with social support and self-esteem $(p<0.01)$. In addition, for the scores of anxiety and depression, GHQ and HADS scale are highly correlated, indicating the consistency of the two scales and a strong validation of anxiety and depression scores.

\section{Comparative Analysis of TB Patients With and Without Drug Resistance}

Two mental health screening scales (HADS and GHQ) demonstrated that MDR-PTB patients were more likely to suffer from probable anxiety and depression than drug sensitive PTB patients without drug resistance. The median anxiety and depression score for the drug resistance patients was 7.0 and 6.5 , for the without drug resistance patients was 3.0 and 2.0, respectively. Because of the heterogeneous of the variance, Mann-Whitney $U$ test was conducted for comparison mental health scores between with drug resistance and without drug resistance groups. MDR-PTB Patients had significantly higher anxiety, depression, self-esteem and stigma scores than patients without drug resistance $(p<0.01)$, and there was no significant difference in total social support scores between the two groups.

\section{Factors Associated With Anxiety and Depression Among Patients With TB}

Multiple linear stepwise regression analysis revealed that selfesteem, drug resistance, perceived TB stigma and duration of TB were statistically significant with anxiety. Self-esteem, social supports, perceived TB stigma and duration of TB were statistically significant with depression (Tables 3, 4).

\section{DISCUSSION}

The inextricable relationship between $\mathrm{TB}$ and mental disorders is well-known although less well-researched. Mental illnesses such as anxiety, depression may have a high comorbidity rate among people suffering from TB (21). However, there is a lack of research on the prevalence of anxiety and depression in Chinese patients with PTB, especially in patients with MDR-TB. We conducted a structured questionnaire in 167 hospitalized TB patients to assess prevalence of depression/anxiety symptoms, TB-related stigma

TABLE 2 | Correlation coefficient and $P$-value between two continuous data.

\begin{tabular}{|c|c|c|c|c|c|c|c|c|c|c|c|}
\hline & $\begin{array}{l}\text { HADS } \\
\text { anxiety }\end{array}$ & $\begin{array}{c}\text { HADS } \\
\text { depression }\end{array}$ & $\begin{array}{c}\text { GHQ- } \\
\text { self- } \\
\text { esteem }\end{array}$ & $\begin{array}{c}\text { GHQ- } \\
\text { depression }\end{array}$ & $\begin{array}{c}\text { GHQ- } \\
\text { anxiety }\end{array}$ & TSS & $\begin{array}{l}\text { Total } \\
\text { score of } \\
\text { social } \\
\text { support }\end{array}$ & $\begin{array}{c}\text { Objective } \\
\text { support } \\
\text { factor }\end{array}$ & $\begin{array}{c}\text { Subjective } \\
\text { supportive } \\
\text { factor }\end{array}$ & $\begin{array}{l}\text { Support- } \\
\text { seeking } \\
\text { behavior }\end{array}$ & $\begin{array}{l}\text { Duration } \\
\text { of disease }\end{array}$ \\
\hline HADS anxiety & 1.000 & & & & & & & & & & \\
\hline HADS depression & $\begin{array}{l}0.814^{\star \star} \\
(0.000)\end{array}$ & 1.000 & & & & & & & & & \\
\hline GHQ- self-esteem & $\begin{array}{c}-.0 .622^{\star \star} \\
(0.000)\end{array}$ & $\begin{array}{c}-0.655^{\star \star} \\
(0.000)\end{array}$ & 1.000 & & & & & & & & \\
\hline GHQ-depression & $\begin{array}{l}0.598^{\star *} \\
(0.000)\end{array}$ & $\begin{array}{l}0.634^{* \star} \\
(0.000)\end{array}$ & $\begin{array}{c}-0.655^{\star \star} \\
(0.000)\end{array}$ & 1.000 & & & & & & & \\
\hline GHQ-anxiety & $\begin{array}{l}0.713^{\star \star} \\
(0.000)\end{array}$ & $\begin{array}{l}0.691^{\star *} \\
(0.000)\end{array}$ & $\begin{array}{c}-.0 .712^{\star \star} \\
(0.000)\end{array}$ & $\begin{array}{l}0.656^{\star \star} \\
(0.000)\end{array}$ & 1.000 & & & & & & \\
\hline TSS & $\begin{array}{l}0.595^{\star \star} \\
(0.000)\end{array}$ & $\begin{array}{l}0.601^{\star \star} \\
(0.000)\end{array}$ & $\begin{array}{c}-0.545^{\star \star} \\
(0.000)\end{array}$ & $\begin{array}{l}0.485^{\star \star} \\
(0.000)\end{array}$ & $\begin{array}{l}0.503^{\star \star} \\
(0.000)\end{array}$ & 1.000 & & & & & \\
\hline Total score of Social Support & $\begin{array}{c}-0.330^{\star \star} \\
(0.000)\end{array}$ & $\begin{array}{c}-0.460^{\star \star} \\
(0.000)\end{array}$ & $\begin{array}{l}0.382^{\star \star} \\
(0.000)\end{array}$ & $\begin{array}{c}-0.416^{\star \star} \\
(0.000)\end{array}$ & $\begin{array}{c}-0.329^{\star \star} \\
(0.000)\end{array}$ & $\begin{array}{c}-0.414^{\star \star} \\
(0.000)\end{array}$ & 1.000 & & & & \\
\hline Objective support factor & $\begin{array}{c}-0.248^{\star \star} \\
(0.001)\end{array}$ & $\begin{array}{c}-0.400^{\star *} \\
(0.000)\end{array}$ & $\begin{array}{l}0.241^{\star \star} \\
(0.002)\end{array}$ & $\begin{array}{c}-0.222^{\star \star} \\
(0.004)\end{array}$ & $\begin{array}{c}-0.196^{\star} \\
(0.011)\end{array}$ & $\begin{array}{c}-0.377^{\star \star} \\
(0.000)\end{array}$ & $\begin{array}{l}0.619^{\star \star} \\
(0.000)\end{array}$ & 1.000 & & & \\
\hline Subjective supportive factor & $\begin{array}{c}-0.213^{\star \star} \\
(0.006)\end{array}$ & $\begin{array}{c}-0.274^{\star *} \\
(0.000)\end{array}$ & $\begin{array}{l}0.308^{\star \star} \\
(0.000)\end{array}$ & $\begin{array}{c}-0.314^{\star \star} \\
(0.000)\end{array}$ & $\begin{array}{c}-0.220^{\star *} \\
(0.004)\end{array}$ & $\begin{array}{c}-0.235^{\star \star} \\
(0.002)\end{array}$ & $\begin{array}{l}0.827^{\star \star} \\
(0.000)\end{array}$ & $\begin{array}{l}0.166^{\star} \\
(0.032)\end{array}$ & 1.000 & & \\
\hline Support-seeking behavior & $\begin{array}{c}-0.275^{\star \star} \\
(0.000)\end{array}$ & $\begin{array}{c}-0.362^{\star \star} \\
(0.000)\end{array}$ & $\begin{array}{l}0.242^{\star \star} \\
(0.002)\end{array}$ & $\begin{array}{c}-0.369^{\star \star} \\
(0.000)\end{array}$ & $\begin{array}{c}-0.329^{\star *} \\
(0.000)\end{array}$ & $\begin{array}{c}-0.328^{\star \star} \\
(0.000)\end{array}$ & $\begin{array}{l}0.602^{\star \star} \\
(0.000)\end{array}$ & $\begin{array}{l}0.305^{\star \star} \\
(0.000)\end{array}$ & $\begin{array}{l}0.260^{\star \star} \\
(0.001)\end{array}$ & 1 & \\
\hline Duration of disease & $\begin{array}{l}0.448^{\star \star} \\
(0.000)\end{array}$ & $\begin{array}{l}0.460^{\star \star} \\
(0.000)\end{array}$ & $\begin{array}{c}-0.388^{\star \star} \\
(0.000)\end{array}$ & $\begin{array}{l}0.452^{\star \star} \\
(0.000)\end{array}$ & $\begin{array}{l}0.356^{\star \star} \\
(0.000)\end{array}$ & $\begin{array}{l}0.287^{\star \star} \\
(0.000)\end{array}$ & $\begin{array}{c}-0.244^{\star \star} \\
(0.001)\end{array}$ & $\begin{array}{c}-0.156^{\star} \\
(0.044)\end{array}$ & $\begin{array}{c}-0.148 \\
(0.056)\end{array}$ & $\begin{array}{c}-0.263^{\star \star} \\
(0.001)\end{array}$ & 1 \\
\hline
\end{tabular}

${ }^{* \star} p<0.01$

${ }^{*} p<0.05$.

The number at the top of the box shows the correlation coefficient, and the number at the bottom of the box shows $P$-value. 
TABLE 3 | Stepwise multiple linear regression analysis results of anxiety.

\begin{tabular}{|c|c|c|c|c|c|c|}
\hline \multirow[t]{2}{*}{ Model } & \multirow[t]{2}{*}{ Variance } & \multicolumn{2}{|c|}{ Unstandardized coefficients } & \multirow{2}{*}{$\begin{array}{c}\text { Standardized coefficients } \\
\beta\end{array}$} & \multirow[t]{2}{*}{$R^{2}$} & \multirow[t]{2}{*}{ Adjusted $R^{2}$} \\
\hline & & $B$ & SE & & & \\
\hline \multirow[t]{2}{*}{1} & (Constant) & 11.238 & 0.650 & & 0.340 & 0.335 \\
\hline & Self-esteem & -0.876 & 0.108 & -0.583 & & \\
\hline \multirow[t]{3}{*}{2} & (Constant) & 8.038 & 0.930 & & 0.432 & 0.423 \\
\hline & Self-esteem & -0.748 & 0.104 & -0.498 & & \\
\hline & Drug resistance & 3.203 & 0.706 & 0.315 & & \\
\hline \multirow[t]{4}{*}{3} & (Constant) & 5.391 & 1.227 & & 0.474 & 0.461 \\
\hline & Self-esteem & -0.584 & 0.113 & -0.388 & & \\
\hline & Drug resistance & 2.496 & 0.718 & 0.246 & & \\
\hline & TB stigma & 0.224 & 0.071 & 0.251 & & \\
\hline \multirow[t]{5}{*}{4} & (Constant) & 4.634 & 1.231 & & 0.502 & 0.486 \\
\hline & Self-esteem & -0.497 & 0.115 & -0.331 & & \\
\hline & Drug resistance & 2.058 & 0.720 & 0.202 & & \\
\hline & TB stigma & 0.224 & 0.069 & 0.251 & & \\
\hline & Duration of tuberculosis & 0.025 & 0.009 & 0.187 & & \\
\hline
\end{tabular}

TABLE 4 | Stepwise multiple linear regression results of depression.

\begin{tabular}{|c|c|c|c|c|c|c|}
\hline \multirow[t]{2}{*}{ Model } & \multirow[t]{2}{*}{ Variance } & \multicolumn{2}{|c|}{ Unstandardized coefficients } & \multirow{2}{*}{$\begin{array}{c}\text { Standardized coefficients } \\
\beta\end{array}$} & \multirow[t]{2}{*}{$R^{2}$} & \multirow[t]{2}{*}{ Adjusted $R^{2}$} \\
\hline & & $B$ & SE & & & \\
\hline \multirow[t]{2}{*}{1} & (Constant) & 11.938 & 0.696 & & 0.385 & 0.380 \\
\hline & Self-esteem & -1.033 & 0.115 & -0.620 & & \\
\hline \multirow[t]{3}{*}{2} & (Constant) & 18.219 & 1.481 & & 0.476 & 0.468 \\
\hline & Self-esteem & -0.838 & 0.115 & -0.503 & & \\
\hline & Social support & -0.219 & 0.046 & -0.324 & & \\
\hline \multirow[t]{4}{*}{3} & (Constant) & 13.245 & 2.191 & & 0.511 & 0.500 \\
\hline & Self-esteem & -0.686 & 0.122 & -0.412 & & \\
\hline & Social support & -0.166 & 0.048 & -0.246 & & \\
\hline & TB stigma & 0.231 & 0.077 & 0.234 & & \\
\hline \multirow[t]{5}{*}{4} & (Constant) & 11.592 & 2.218 & & 0.539 & 0.525 \\
\hline & Self-esteem & -0.593 & 0.124 & -0.356 & & \\
\hline & Social support & -0.151 & 0.047 & -0.223 & & \\
\hline & TB stigma & 0.226 & 0.075 & 0.228 & & \\
\hline & Duration of tuberculosis & 0.027 & 0.010 & 0.182 & & \\
\hline
\end{tabular}

and social support in patients, and to explore the impact of other factors on psychological health problems.

The prevalence of probable anxiety and depression in this TB population was 29.34 and $29.94 \%$ according to the HADS. Other studies determined that the prevalence of anxiety among patients with TB ranged from $18.37 \%$ in the China to $47.2 \%$ among hospitalized patients in Pakistan (3, 4), the prevalence of depression among patients with $\mathrm{TB}$ ranged from 17.73 to $48 \%$ in China $(4,7)$. This result is consistent with the findings of the prevalence of anxiety and depression noted among patients enrolled in previous studies, which suggests there is a higher prevalence of mental illness among TB patients. Our study also noted a strong positively correlation between the anxiety and depression scores of HADS and GHQ-20, which indicates our outcome of anxiety and depression have good reliability and validity.

Compared to TB patients without drug resistance, our study indicated that MDR-PTB patients were more likely to suffer from anxiety, depression, TB-related stigma and low self- affirmation. This is the first report to compare the psychological health problem, TB-stigma and social support between TB patients with and without drug resistance in China. This is consistent with a previous research in Serbia, which showed that MDR-TB cases are almost three times more frequently experienced subjective feeling of nervousness, sadness, used sedatives and stigma associated with TB compared to drug susceptible respondents (22). TB is stigmatized because of its associations with HIV, poverty, low social class, malnutrition, or disreputable behavior (10). MDR-TB patients are particularly affected having in mind 
long (20 month) and arduous treatment, regime consisted of powerful anti-TB drugs with severe side-effects that can affect mental health, higher case fatality and lower cure rate (23). Furthermore, the high score of psychological health problem noted among drug resistance TB patients may be associated with higher TB-related stigma and longer duration of treatment, which is more common in patients with drug resistance than patients without drug resistance. This could be concluded that drug resistance, TB-stigma and self-esteem have an influence on psychological health among TB patients.

One of the factors significantly associated with anxiety and depression was self-esteem. A previous study with hospitalized patients with $\mathrm{TB}$, which showed that self-esteem scores dropped in accordance with category of depression, revealing that low self-esteem is a characteristic of depression (24). Besides, a study in Indonesia found a significant correlation between self-esteem with the incidence of anxiety in patients with MDR-TB (25). Stigmatization, negative emotions, social rejection, and isolation were reported by TB patients and could contribute to low selfesteem and impairment of psychosocial well-being (26). The reason of MDR-PTB patients have lower self-esteem might be that they had experienced more lacks of control over their selfcare activities, more financial stress due to the longer duration of treatment, more restrictions on recreational and social activities, loss of independence, early retirement, role alterations and disruption in family life, then lead to the altered self-image and diminished self-esteem (27).

It's worth noting that poor social support was only significantly associated with depression and multi-drug resistance was only significantly associated with anxiety. This could indicate that lack of (poor) social support may lead to increased depression symptom and multi-drug resistance may more likely associated with anxiety symptom. On the other hand, good social support is vital for those with good health in prevention of depression, and multi-drug resistance have a greater contribution to anxiety symptoms.

In this study we found low self-esteem, high TB-related stigma and long duration of $\mathrm{TB}$ are all risk factors for psychological problems. We also found multi-drug resistance is riskier especially for anxiety, lower social support is risker for depression. Besides, MDR-PTB patients were more likely to suffer from anxiety, depression, TB-related stigma and low selfaffirmation than drug sensitive PTB patients, which suggests that the whole society, from family members, doctors to government, need to pay attention to the mental health of MDR-PTB patients. In addition, measures to reduce psychological distress

\section{REFERENCES}

1. Dheda K, Gumbo T, Gandhi NR, Murray M, Theron G, Udwadia Z, et al. Global control of tuberculosis: from extensively drug-resistant to untreatable tuberculosis. Lancet Respir Med. (2014) 2:321-38. doi: 10.1016/S2213-2600(14)70031-1

2. Annabel B, Dean A, Hannah M. Global Tuberculosis Report 2019. Geneva: World Health Organization (2019). among patients with $\mathrm{TB}$ should include a more comprehensive care approach which include psychological treatment, family support, social support, government unemployment support and economic compensation. Limitations of sample size in this study should be considered, the results in current study should be further verified in studies with larger sample size. Furthermore, whether related psychopharmacological interventions can improve the mental state of TB patients should be further researched.

\section{DATA AVAILABILITY STATEMENT}

The original contributions presented in the study are included in the article/supplementary material, further inquiries can be directed to the corresponding authors.

\section{ETHICS STATEMENT}

The studies involving human participants were reviewed and approved by Institutional Ethical Review Board of Beijing Chest Hospital, Beijing, China. The patients/participants provided their written informed consent to participate in this study.

\section{AUTHOR CONTRIBUTIONS}

LZ and LG designed the study and drafted the manuscript. YZ performed the experiments. KL, SQ, and WY performed clinical examination. All authors contributed to the article and approved the submitted version.

\section{FUNDING}

This study was supported by the grant from the Ministry of Science and Technology, People's Republic of China (2018ZX10302302001009); this study was also supported by Beijing Municipal Administration of Hospitals Clinical Medicine Development of Special Funding Support (ZYLX201824) and Beijing Municipal Administration of Hospitals' Ascent Plan (DFL20181602). This work was also supported by CAS Key Laboratory of Mental Health, Institute of Psychology, Chinese Academy of Sciences.

\section{ACKNOWLEDGMENTS}

We thank our colleagues in CAS Key Laboratory of Mental Health, Institute of Psychology, Chinese Academy of Sciences. patients in Pakistan. Clin Pract Epidemiol Ment Health. (2008) 4:4. doi: 10.1186/1745-0179-4-4

4. Wang XB, Li XL, Zhang Q, Zhang J, Chen HY, Xu WY, et al. A survey of anxiety and depressive symptoms in pulmonary tuberculosis patients with and without tracheobronchial tuberculosis. Front Psychiatry. (2018) 9:308. doi: 10.3389/fpsyt.2018.00308 
5. Moussas G, Tselebis A, Karkanias A, Stamouli D, Ilias I, Bratis D, et al. A comparative study of anxiety and depression in patients with bronchial asthma, chronic obstructive pulmonary disease and tuberculosis in a general hospital of chest diseases. Ann Gen Psychiatry. (2008) 7:7. doi: 10.1186/1744-859X-7-7

6. Ige OM, Lasebikan VO. Prevalence of depression in tuberculosis patients in comparison with non-tuberculosis family contacts visiting the DOTS clinic in a Nigerian tertiary care hospital and its correlation with disease pattern. Ment Health Fam Med. (2011) 8:235-41.

7. Gong Y, Yan S, Qiu L, Zhang S, Lu Z, Tong Y, et al. Prevalence of depressive symptoms and related risk factors among patients with tuberculosis in China: a multistage cross-sectional study. Am J Trop Med Hyg. (2018) 98:1624-8. doi: 10.4269/ajtmh.17-0840

8. Man MA, Necrelescu OL, Bondor C, Trofor A, Alexandrescu D, Dantes E. Depressive syndrome, anxiety and illness perception in Tuberculosis patients. Recent Res Mod Med. (2011) 978:243-8. Available online at: http://www.wseas. us/e-library/conferences/2011/Cambridge/MEDICAL/MEDICAL-28.pdf

9. Pachi A, Bratis D, Moussas G, Tselebis A. Psychiatric morbidity and other factors affecting treatment adherence in pulmonary tuberculosis patients. Tuberc Res Treat. (2013) 2013:1-37. doi: 10.1155/2013/489865

10. Courtwright A, Turner AN. Tuberculosis and stigmatization: pathways and interventions. Public Health Rep. (2010) 125(Suppl. 4):34-42. doi: 10.1177/00333549101250S407

11. Peltzer K, Louw J. Prevalence of suicidal behaviour and associated factors among tuberculosis patients in public primary care in South Africa. Indian J Med Res. (2013) 138:194-200.

12. Simonovska L, Trajcevska M, Mitreski V, Simonovska I. The causes of death among patients with tuberculosis. Eur Respir J. (2015) 46(Suppl. 59):PA2713. doi: 10.1183/13993003.congress-2015. PA2713

13. Molla A, Mengesha A, Derajew H, Kerebih H. Suicidal ideation, attempt, and associated factors among patients with tuberculosis in ethiopia: a crosssectional study. Psychiatry J. (2019) 2019:4149806. doi: 10.1155/2019/41 49806

14. Yang Y, Ding R, Hu D, Zhang F, Sheng L. Reliability and validity of a Chinese version of the HADS for screening depression and anxiety in psycho-cardiological outpatients. Compr Psychiatry. (2014) 55:215-20. doi: 10.1016/j.comppsych.2013.08.012

15. Zigmond AS, Snaith RP. The hospital anxiety and depression scale. Acta Psychiatr Scand. (1983) 67:361-70. doi: 10.1111/j.1600-0447.1983.tb09716.x

16. Bjelland I, Dahl AA., Haug TT, Neckelmann, D. The validity of the Hospital Anxiety and Depression Scale. an updated literature review. J Psychosom Res. (2002) 52:69-77. doi: 10.1016/s0022-3999(01)00296-3

17. $\mathrm{Li} \mathrm{H}$, Boey $\mathrm{K}$. Assessing psychological well-being of college students: Psychometric properties of GHQ-20. Psychol Develop Educ. (2002) 18:75-9. doi: 10.16187/j.cnki.issn1001-4918.2002.01.016

18. Yang TT. Development and evaluation of tuberculosis-related stigma scale. Pubic Health Prev Med. (2016) 27:46-8. Available online at: https://oversea.cnki.net/KCMS/detail/detail.aspx?dbcode=CJFD\&dbname= CJFDLAST2017\&filename $=$ FBYF201606013\&v $=0$ GuPfaNwjV1ULZl12PSVm ZWHrJ0OJqLYxffiY3mhZbaJ2FOR1tCRGRR6nwd\%25mmd2FmLKh
19. Xiao S. The theoretical basis and research application of social support rating scale. J Clin Psychiatry. (1994) 4:98-100. Available online at: https://kns.cnki.net/kcms/detail/detail.aspx?dbcode=CJFD\&db name $=$ CJFD9495\&filename $=$ LCJS402.019\&v=RIJnzeopx9rCnYsXFSYYR61bMGb C5ivTFhU4t896EDTXCOFnok\%25mmd2FQ82xshcQ3Ywmm

20. Ke X, Liu C, Li N. Social support and Quality of Life: a cross-sectional study on survivors eight months after the 2008 Wenchuan earthquake. BMC Public Health. (2010) 10:573. doi: 10.1186/1471-2458-10-573

21. Janse Van Rensburg A, Dube A, Curran R, Ambaw F, Murdoch J, Bachmann $\mathrm{M}$, et al. Comorbidities between tuberculosis and common mental disorders: a scoping review of epidemiological patterns and person-centred care interventions from low-to-middle income and BRICS countries. Infect Dis Poverty. (2020) 9:4. doi: 10.1186/s40249-019-0619-4

22. Stosic M, Vukovic D, Babic D, Antonijevic G, Foley KL, Vujcic I, et al. Risk factors for multidrug-resistant tuberculosis among tuberculosis patients in Serbia: a case-control study. BMC Public Health. (2018) 18:1114. doi: 10.1186/s12889-018-6021-5

23. WHO. Companion Handbook to the WHO Guidelines for the Programmatic Management of Drug-Resistant Tuberculosis. World Health Organization, Geneva. (2014).

24. Westaway MS, Wolmarans L. Depression and self-esteem: Rapid screening for depression in black, low literacy, hospitalized tuberculosis patients. Soc Sci Med. (1992) 35:1311-5. doi: 10.1016/0277-9536(92)90184-R

25. Fitrianur W, Soeharto S, Supriati L. Self-esteem as predictor of anxiety and depression on patients of multidrug resistant tuberculosis (MDR-TB). Int J Psychiatr Nurs. (2019) 5:37. doi: 10.5958/2395-180X.2019.00026.4

26. Santos APCD, Lazzari TK, Silva DR. Health-related quality of life, depression and anxiety in hospitalized patients with tuberculosis. Tuberc Respir Dis. (2017) 80:69. doi: 10.4046/trd.2017.80.1.69

27. Kara Kaşikçi M, Alberto J. Family support, perceived self-efficacy and self-care behaviour of Turkish patients with chronic obstructive pulmonary disease. $J$ Clin Nurs. (2007) 16:1468-78. doi: 10.1111/j.1365-2702.2006.01782.x

Conflict of Interest: The authors declare that the research was conducted in the absence of any commercial or financial relationships that could be construed as a potential conflict of interest.

Publisher's Note: All claims expressed in this article are solely those of the authors and do not necessarily represent those of their affiliated organizations, or those of the publisher, the editors and the reviewers. Any product that may be evaluated in this article, or claim that may be made by its manufacturer, is not guaranteed or endorsed by the publisher.

Copyright (C) 2021 Liu, Zhang, Qu, Yang, Guo and Zhang. This is an open-access article distributed under the terms of the Creative Commons Attribution License (CC $B Y)$. The use, distribution or reproduction in other forums is permitted, provided the original author(s) and the copyright owner(s) are credited and that the original publication in this journal is cited, in accordance with accepted academic practice. No use, distribution or reproduction is permitted which does not comply with these terms. 